\title{
Sanitização com produto à Base de Cloro e com Ozônio: Efeito Sobre Compostos Bioativos de Amora-preta (rubus fruticosus) cv. Tupy
}

\author{
Andressa Carolina Jacques ${ }^{1 *}$, Rui Carlos Zambiazi ${ }^{2}$, Eliézer Ávila Gandra ${ }^{3}$, Fernanda Krumreich ${ }^{4}$, \\ Suzane, Rickies da Luz $^{4}$, Mirian Ribeiro Galvão Machado ${ }^{5}$ \\ http://dx.doi.org/10.1590/0034-737X201562060001
}

\begin{abstract}
RESUMO
O objetivo deste trabalho foi avaliar e comparar a eficiência da sanitização de amora-preta, com diferentes concentrações e tempos de imersão em hipoclorito de sódio e com ozônio, e avaliar a influência do processo sobre os compostos bioativos do produto. Foram feitas análises microbiológicas e a determinação dos compostos bioativos. Os compostos de cloro utilizados na sanitização induziram a perdas significativas dos compostos bioativos (compostos fenólicos, antocianinas, tocoferóis, ácido ascórbico e carotenoides), presentes na amora-preta, sendo eficientes na sanitização contra fungos, quando utilizados na concentração de 200 ppm e por 15 minutos de imersão. Já os frutos sanitizados com ozônio apresentaram adequação aos padrões microbiológicos (fungos, coliformes totais e termotolerantes, Escherichia coli e Salmonella spp) estabelecidos pela legislação, e não apresentaram alterações significativas no conteúdo dos compostos bioativos, sendo que a menor concentração de ozônio presente neste estudo apresentou maior eficácia na sanitização dos frutos, comparada com as soluções de cloro utilizadas.
\end{abstract}

Palavras-chave: bioativos, Cloro, Ozônio.

\section{ABSTRACT}

\section{Sanitization by Chlorine compounds and Ozone: Effect on Bioactive Compounds of Blackberry (Rubus fruticosus) cv. Tupy}

The aim of this study was to evaluate and compare the efficiency of sanitization of blackberry with sodium hypochlorite and ozone and evaluate the influence of this procedure on bioactive compounds in different concentrations and immersion times. Microbiological analyzes and determination of bioactive compounds were carried out. The chlorine compounds used in the sanitization induced losses of blackberry bioactive compounds, but were effective in sanitizing against fungi at the concentration of $200 \mathrm{ppm}$ in immersion for 15 minutes. Fruits sanitized with ozone had appropriate microbiological standards (fungi, total coliforms and thermotolerant, Escherichia coli and Salmonella spp) established by legislation, and no significant changes in the content of bioactive compounds, with the lowest concentration of ozone present in this study showing the greatest efficacy in fruit sanitation compared with the chlorine solutions used.

Key words: bioactive, Chlorine, Ozone.

\footnotetext{
Submetido em 19/03/2014 e aprovado em 28/07/2015

${ }^{1}$ Universidade Federal do Pampa, Curso de Engenharia de Alimentos, Bagé, Rio Grande do Sul, Brasil. andressa.jacques@yahoo.com.br

${ }^{2}$ Universidade Federal de Pelotas, Centro de Ciências Químicas, Farmacêuticas e de Alimentos, Pelotas, Rio Grande do Sul, Brasil. zambiazi@gmail.com

${ }^{3}$ Universidade Federal de Pelotas, Centro de Ciências Químicas, Farmacêuticas e de Alimentos, Pelotas, Rio Grande do Sul, Brasil. gandraea@hotmail.com

${ }^{4}$ Universidade Federal de Pelotas, Departamento de Ciência e Tecnologia Agroindustrial, Pelotas, Rio Grande do Sul, Brasil. nandaalimentos@gmail.com; suzanerickes@gmail.com

5 Universidade Federal de Pelotas, Centro de Ciências Químicas, Farmacêuticas e de Alimentos, Pelotas, Rio Grande do Sul, Brasil. miriangalvao@gmail.com

*Autora para correspondência: andressa.jacques@yahoo.com.br
} 


\section{INTRODUÇÃO}

O Brasil é o principal produtor mundial de frutas in natura, porém, pela rápida perecibilidade, grande parte dessas frutas deteriora-se em poucos dias, tendo sua comercialização dificultada, especialmente quando transportadas por longas distâncias. Em função disto, a produção de polpas de frutas tem-se destacado como importante alternativa para o aproveitamento dos frutos durante a safra, permitindo a estocagem das polpas fora da época de produção dos frutos in natura (Brunini et al., 2002). Segundo a legislação brasileira do Ministério da Agricultura, polpa é o produto não fermentado, não concentrado ou diluído, obtido pelo esmagamento de frutos polposos (Brasil, 2000).

A amora-preta (blackberry) é um dos frutos que apresenta alta perecibilidade. Este fruto pertence ao gênero Rubus, que contém, aproximadamente, 740 espécies, classificadas, por alguns autores, entre 12 e 15 subgêneros (Jennings, 1988, apud Daubeny, 1996). Dada sua alta taxa respiratória, e, por consequência, curta vida útil, uma alternativa para aumentar a oferta do produto é a produção de sua polpa. Os frutos, principalmente os que apresentam coloração vermelha e,ou azul, como a amora-preta, são importantes fontes de compostos bioativos para dietas alimentares. Essas cores são características das antocianinas, compostos fenólicos pertencentes à classe dos flavonoides. Muitos desses compostos apresentam uma gama de efeitos biológicos, incluindo ação antioxidante, antimicrobiana, anti-inflamatória e vasodilatadora (Degáspari \& Waszczynsky, 2004).

No entanto, frutos, em geral, quando não manipulados e, ou, processados com controle higiênico adequado, podem ser potenciais veiculadores de micro-organismos que, inclusive, podem estar associados à infecções ou intoxicações alimentares e, consequentemente, a doenças transmitidas por alimentos (DTA). Sanitizantes contendo compostos de cloro, incluindo hipocloritos de sódio e de cálcio, são amplamente utilizados em várias etapas do processamento de frutos, para minimizar a veiculação de doenças transmitidas por micro-organismos. O tratamento com cloro, para ser efetivo no controle bacteriológico, depende de alguns fatores, como $\mathrm{pH}$, concentração de cloro ativo da solução e tempo de ação do sanitizante, os quais são determinantes para a eficácia do efeito antimicrobiano (Banwart, 1989; Andrade \& Martyn, 1996). Por ser um agente oxidante, o cloro livre pode reagir com compostos orgânicos sintéticos e naturais, participando de reações de oxidação e substituição, em que suas moléculas são adicionadas às moléculas denominadas precursoras. As reações que envolvem o cloro residual livre e os compostos orgâni- cos naturais (CONs) são extremamente complexas, já que estes compostos apresentam elevada diversidade de grupos funcionais aromáticos, carboxílicos, fenólicos, bem como quantidades variáveis de duplas e triplas ligações, que são passíveis de ataque pelo agente oxidante (Filho \& Sakaguti, 2008).

Nos últimos anos, tem sido crescente a preocupação com o uso do hipoclorito e dos demais sais de cloro em alimentos, por serem considerados precursores de cloraminas orgânicas, as quais são prejudiciais à saúde humana por seu alto potencial carcinogênico. Com isto, tem sido incentivada a pesquisa com novos agentes sanitizantes que não gerem resíduos, surgindo a opção da utilização de ozônio como sanitizante de alimentos.

A ozonização passou a ser utilizada no Brasil como alternativa aos métodos convencionais de pré-cloração e pré-aeração, no tratamento de águas superficiais, a partir de 1983 (Lapolli et al., 2003). Na área de alimentos, poucas pesquisas têm sido realizadas no Brasil e ainda não existe legislação específica que oriente suas aplicações.

Em face do exposto, o objetivo deste trabalho foi avaliar e comparar a eficiência da sanitização de amorapreta cv Tupy com hipoclorito de sódio e com ozônio e avaliar a influência do processo de sanitização sobre os compostos bioativos presentes nos frutos.

\section{MATERIAL E METODOS}

Cerca de $3 \mathrm{~kg}$ de amora-preta cv. Tupy, da safra de 2010, foram coletados de uma área experimental, localizada na cidade de Pelotas, RS ( $31^{\circ} 46^{\prime} 19^{\prime \prime} \mathrm{S}-52^{\circ}$ $20^{\prime} 33^{\prime \prime}$ O). Frutos sem podridão visível foram selecionados e submetidos ao processo de sanitização. Uma porção dos frutos foi submetida à cloração e outra, à ozonização.

\section{Processo de sanitização}

A cloração foi realizada pela imersão dos frutos em soluções de água clorada, feitas a partir de hipoclorito de sódio a $10 \%$. As concentrações das soluções utilizadas foram de 0, 50, 100, 150 e 200 ppm de cloro. Porções distintas dos frutos foram submetidas a cada uma das soluções, pelos períodos de imersão de cinco e de 15 minutos, com três repetições.

A ozonização foi realizada, borbulhando-se o gás ozônio em água destilada, a $2{ }^{\circ} \mathrm{C}$, por 15 minutos (residual de $1,75 \mathrm{ppm}$ ), 30 minutos (residual de $3 \mathrm{ppm}$ ) e $1 \mathrm{~h}$ (residual de $4 \mathrm{ppm}$ ). Para isso, foi utilizado um equipamento gerador de ozônio (Trata OZ, modelo TLS 6A), cedido pela empresa OZ Engenharia Ltda. (RS), o qual se fundamenta no efeito corona, ou seja, na geração de ozô- 
nio pela descarga elétrica sobre o oxigênio. $\mathrm{O}$ residual de ozônio na água foi medido pelo método Padrão do índigo, aceito pelo United States Environmental Protection Agency (EPA) e pelo International Ozone Association (IOA), sendo o único método a constar no Standards methods for the examination of water and wastewater.

Depois de sanitizados, os frutos foram processados na forma de polpa, pela trituração em liquidificador, sem realizar a separação das sementes. A polpa obtida foi acondicionada em embalagens de polietileno de alta densidade $(0,45 \mu \mathrm{m})$ e congelada, a $-80{ }^{\circ} \mathrm{C}$, até o momento das análises. Para evitar a contaminação cruzada, os equipamentos e utensílios utilizados no processamento foram higienizados com solução de $\mathrm{NaOCl}$ a 200ppm (200 mg. $\left.\mathrm{L}^{-1}\right)$.

\section{Análises microbiológicas}

As análises microbiológicas foram realizadas, seguindo-se os procedimentos propostos por autores. Para as determinações microbiológicas, $25 \mathrm{~g}$ de polpa foram transferidas assepticamente para frascos com $225 \mathrm{~mL}$ de água peptonada estéril (diluição $10^{-1}$ ). A partir dessa diluição, foram feitas as diluições seriadas, até $10^{-4}$, com o mesmo diluente, sendo todas avaliações realizadas de acordo com Downes \& Ito (2001) \& Silva et al. (1997).

\section{Quantificação de fungos (bolores e leveduras)}

Para a contagem de bolores e leveduras, foi utilizado o método de plaqueamento direto em superfície de Ágar Batada Dextrose. Diluições $10^{-1}, 10^{-2}, 10^{-3}$ e $10^{-4}$ foram inoculadas por espalhamento e submetidas à incubação, a $25^{\circ} \mathrm{C}$. Foram realizadas contagens aos três e aos cinco dias.

\section{Enumeração de coliformes totais $e$ termotolerantes}

Para a contagem de coliformes totais e termotolerantes, foi utilizada a técnica do Número Mais Provável (NMP). A análise presuntiva de coliformes foi realizada em Caldo Lauril Sulfato de Sódio (LST), com incubação, a $35^{\circ} \mathrm{C}$, por 48 horas. A enumeração de coliformes totais foi efetuada em Caldo Lactosado Bile Verde Brilhante (CLBVB), com incubação, a $35^{\circ} \mathrm{C}$, por 24 horas. A enumeração de coliformes termotolerantes foi realizada em Caldo Escherichia coli (EC), com incubação, a $45,5^{\circ} \mathrm{C}$, por 24 e 48 horas.

\section{Isolamento de Escherichia coli}

A partir dos tubos positivos de caldo EC realizou-se semeadura em placas com meio de cultura Eosin Methylene Blue Agar (EMB). As placas foram incubadas, a $37{ }^{\circ} \mathrm{C}$, por 24 horas. As colônias com morfologia característica de E. coli foram identificadas por meio dos testes de produção de indol, reações de vermelho de metila e Voges-Proskauer, e utilização de citrato.

\section{Isolamento de Salmonella spp.}

Para o isolamento de Salmonella spp., foi realizado pré-enriquecimento em água peptonada tamponada, a 37 ${ }^{\circ} \mathrm{C}$, por 24 horas, seguido de enriquecimento seletivo em Caldo Rappaport-Vassiliadis, a $42{ }^{\circ} \mathrm{C}$, por 24 horas e Caldo Tetrationato, a $37{ }^{\circ} \mathrm{C}$, por 24 horas. Em seguida, foi feita semeadura em placas com ágares desoxicolatolisina-xilose (XLD) e Hektoen-enteric (HE), sendo ambos incubados, por $24 \mathrm{~h}$, a $37^{\circ} \mathrm{C}$. Colônias típicas foram submetidas à identificação bioquímica em Ágar Tríplice Ferro, Ágar Lisina Ferro e Ágar Urease, a $37^{\circ} \mathrm{C}$, por 24 horas. As amostras que apresentaram reação bioquímica característica foram submetidas à identificação sorológica, utilizando-se os soros polivalentes antissalmonella somático e flagelar (Probac).

\section{Análises químicas}

\section{Quantificação de compostos fenólicos}

Os compostos fenólicos foram extraídos da polpa das frutas, usando-se o método descrito por Häkkinen et al. (1998). Uma alíquota de $30 \mu \mathrm{L}$ do extrato obtido foi usada para a análise cromatográfica.

O cromatógrafo consistiu no sistema HPLCShimadzu, provido de injetor automático, detector UVvisível a $280 \mathrm{~nm}$, coluna de fase reversa RP-18 CLCODS (5 $\mu \mathrm{m}, 4,6$ mm x $150 \mathrm{~mm}$-marca), com fase estacionária octadecil e uma coluna de guarda CLC-GODS (4), com fase estacionária de superfície octadecil, ambas alocadas em forno a $25{ }^{\circ} \mathrm{C}$. A fase móvel consistiu no gradiente de eluição, utilizando-se solução aquosa de ácido acético $(99: 1 \mathrm{v} / \mathrm{v})$ e metanol, com fluxo de 0,8 $\mathrm{mL} / \mathrm{min}$, com um tempo total de corrida de 45 minutos, segundo metodologia descrita por Zambiazi (1997).

\section{Determinação de antocianinas}

A determinação de antocianinas foi realizada, utilizando-se etanol acidificado para a extração, já que se trata de um composto hidrossolúvel, estável em meio ácido, seguindo-se método original (Lees \& Francis, 1972). O cálculo do conteúdo total de antocianinas foi baseado na Lei de Beer e os resultados foram expressos em mg de cianidina 3-glicosídio por $100 \mathrm{~g}^{-1}$ de amostra, sendo a leitura realizada em espectrofotômetro Marca Ultrospec 2000.

\section{Determinação de tocoferóis}

Para a extração de tocoferóis, foi utilizada acetona como solvente extrator. Foram injetados $20 \mu \mathrm{L}$ do extrato obtido no mesmo sistema HPLC-Shimadzu, usado 
para a análise de compostos fenólicos, equipado com detector de fluorescência, utilizando-se os comprimentos de onda de $290 \mathrm{~nm}$, para excitação, e de $330 \mathrm{~nm}$, para a emissão. A separação dos compostos foi efetuada, utilizando-se um sistema gradiente de eluição e utilizando-se, como fases móveis, metanol, acetonitrila e isopropanol, seguindo-se a metodologia adaptada de Zambiazi (1997).

\section{Determinação de ácido ascórbico}

A extração de ácido L-ascórbico foi realizada de acordo com Ayham et al. (2001). A análise por cromatografia líquida de alta eficiência foi feita no mesmo sistema HPLC-Shimadzu, usado para a análise de compostos fenólicos, utilizando-se o detector UV-visível a $254 \mathrm{~nm}$. A separação dos compostos foi desenvolvida, utilizando-se um sistema de gradientes, com as fases móveis, contendo água ultra pura:ácido acético $(99,9: 0,1, \mathrm{v} / \mathrm{v})$ e metanol, com fluxo de $0,8 \mathrm{~mL} \cdot \mathrm{min}^{-1}$.

\section{Determinação de carotenoides}

O processo de extração dos carotenoides foi realizado, utilizando-se a mesma metodologia descrita por Rodriguez-Amaya (2001). Após a etapa de extração, foi realizada a saponificação da amostra, adicionando-se 25 $\mathrm{mL}$ de solução de $\mathrm{KOH}$ 1,5 N em etanol, em $25 \mathrm{~mL}$ de amostra, deixando-se em repouso, na ausência de luz, por $18 \mathrm{~h}$. Após a separação das fases, o extrato foi concentrado em rotaevaporador, a $35^{\circ} \mathrm{C}$, e dissolvido em metanol: acetonitrila, 30:70 v/v. O extrato diluído foi transferido para tubos de eppendorf e centrifugado, a $9000 \mathrm{rpm}$, por seis minutos. O sobrenadante $(25 \mu \mathrm{L})$ foi injetado no cromatógrafo líquido de alta eficiência.

A análise por cromatografia líquida de alta eficiência foi feita no mesmo sistema HPLC-Shimadzu, usado para a análise de compostos fenólicos, equipado com detector UV-Visível, utilizando-se o comprimento de onda de $450 \mathrm{~nm}$.

A separação foi efetuada, utilizando-se um sistema gradiente de eluição, composto de metanol, acetonitrila e acetato de etila, com um fluxo de $1 \mathrm{~mL} / \mathrm{min}$. Rodriguez-Amaya (2001).

\section{RESULTADOS E DISCUSSÃO}

A resolução RDC n ${ }^{\circ}$ 12, de 02/01/2001 (Brasil, 2001), que estabelece os padrões microbiológicos para alimentos e o limite máximo de $10^{2} \mathrm{NMP}^{-1}{ }^{-1}$, para coliformes termotolerantes, porém não estabelece padrões para fungos. No entanto, de acordo a Instrução normativa $\mathrm{n}^{\circ} 1$, de 07 de janeiro de 2000, a polpa de fruta deverá observar os seguintes limites microbiológicos: soma de bolores e leveduras (fungos), no máximo $5 \times 10^{3} \mathrm{~g}^{-1}$ para polpa "in-natura”, congelada ou não;

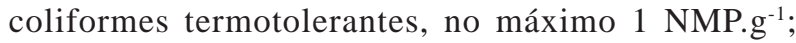
Salmonella: ausência em $25 \mathrm{~g}$.

Nas Tabelas 1 e 2 estão os resultados das análises microbiológicas para bolores e leveduras, coliformes totais e termotolerantes e Salmonella spp. das frutas sanitizadas com cloro e ozônio, respectivamente.

Na Tabela 1, observa-se que a sanitização das frutas com concentrações de cloro, iguais a 0,50 e 150 ppm, não foi eficiente para manter os níveis de fungos dentro dos parâmetros estipulados pelo anexo I, do Regulamento técnico geral para fixação dos padrões de identidade e qualidade para polpa de fruta, da Instrução normativa $\mathrm{n}^{\circ}$ 1, de 07 de janeiro de 2000. Com a sanitização com cloro a 200 ppm, por cinco e 15 minutos, apenas a amostra que ficou imersa por 15 minutos na solução clorada apresentou níveis de bolores e leveduras aceitáveis. Antoniolli (2005) também encontrou melhores resultados de sanitização com NaOCl, na concentração de $200 \mathrm{mg}$.L-1 de cloro ativo, em experimentos em que abacaxis foram sanitizados com cloro.

No entanto, pelos resultados da Tabela 2, observa-se que todas as concentrações de ozônio utilizadas foram eficientes para redução de fungos aos níveis recomendados.

Nascimento et al. (1999), ao estabelecerem o perfil microbiológico de polpas produzidas e comercializadas na cidade de São Luís, MA, constataram que $100 \%$ das amostras apresentaram contaminação por bolores e leveduras, apresentando contagens entre $1,0 \times 10^{5}$ e $1,1 \mathrm{x}$ $10^{8}$ UFC. $g^{-1}$. Segundo Franco \& Landgraf (2003), baixas contagens de bolores e leveduras são consideradas normais (não significativas) em alimentos frescos e congelados. No entanto, contagens elevadas representam, além do aspecto deteriorante, que pode levar inclusive à rejeição do produto, um risco à saúde pública, pela possível produção de micotoxinas por algumas espécies de fungos filamentosos.

A Legislação Brasileira, ANVISA - Resolução RDC12 (Brasil, 2001), estabelece o limite de 5 x $10^{2}$ UFC de coliformes fecais por grama, para frutas, produtos de frutas e similares - frescas, in natura, preparadas (descascadas ou selecionadas ou fracionadas), sanitizadas, refrigeradas ou congeladas para consumo direto. $\mathrm{O}$ baixo valor de $\mathrm{pH}$ apresentado pela maioria das polpas poderia representar um fator limitante para o crescimento de bactérias patogênicas, o que manteria os índices de contaminação bacteriana em níveis baixos. $\mathrm{O}$ pH da amora-preta cv. Tupy é em torno de 3,23, porém, neste estudo, ocorreu a presença de coliformes totais e termotolerantes mesmo na polpa sanitizada, por $5 \mathrm{~min}$, na concentração de 50 ppm de cloro, não sendo, portanto, o baixo $\mathrm{pH}$ um fator que tenha impedido a contaminação por esses grupos microbianos. Contaminação por 
coliformes totais e termotolerantes também foi verificada em outras polpas de frutas com $\mathrm{pH}$ baixo, como, por exemplo, em polpa de maracujá, conforme o estudo realizado por Leite et al. (2000) e Lima et al. (2001) segundo os quais a contaminação estaria, provavelmente, associada à manipulação inadequada durante o processamento da matéria-prima, ou, ainda, seria devida à contaminação cruzada com superfícies de equipamentos inadequadamente higienizados. Com relação às amostras sanitizadas com ozônio, não foi evidenciada a presença de coliformes totais e termotolerantes, em qualquer um dos tratamentos realizados, demostrando a eficácia do ozônio contra estes micro-organismos. Com relação à Salmonella spp. e à E. coli, não foi observada em amostra alguma a presença desses micro-organismos, tanto nas sanitizadas com ozônio quanto nas sanitizadas com cloro.

Na comparação entre os dois métodos de sanitização, ficou evidenciada a maior eficácia do ozônio. Porém, outros fatores podem ter influenciado esses resultados, pois a ação dos compostos de cloro depende da concentração da forma ativa (ácido hipocloroso), $\mathrm{pH}$, espécie e quantidade de micro-organismo a ser destruída, e, também, das características físico-químicas da água, do tempo de contato e da temperatura. No caso específico das polpas de amora-preta cv Tupy, o $\mathrm{pH}$ da polpa $(3,23)$ pode ter sido o fator responsável pela menor eficácia da solu- ção de cloro, em comparação com a do ozônio, pois compostos de cloro tornam-se mais eficazes como sanitizantes em faixas de $\mathrm{pH}$ entre 6,5 e 7,0, perdendo eficácia em pHs distantes destes valores.

Outra vantagem que deve ser considerada, em relação aos dois sanitizantes: é a menor quantidade de resíduos gerada pelo ozônio, em comparação com a gerada pelo cloro, já que compostos de cloro, quando utilizados de maneira inadequada, podem formar organoclorados, provenientes da reação da matéria orgânica presente com o cloro, enquanto o ozônio praticamente não deixa resíduos (Lapolli et al., 2003).

Na Tabela 3, estão os resultados do conteúdo de compostos fenólicos e do total de antocianinas das frutas sanitizadas com cloro e ozônio.

Por ser um agente oxidante, o cloro livre pode reagir com compostos orgânicos sintéticos e naturais, participando de reações de oxidação e substituição, em que moléculas de cloro são adicionadas às moléculas denominadas precursoras. As reações que envolvem o cloro residual livre e os compostos orgânicos naturais (CONs) são extremamente complexas, uma vez que os compostos orgânicos apresentam uma elevada diversidade de grupos funcionais aromáticos, carboxílicos, fenólicos, bem como grandes quantidades de duplas e triplas ligações, além de serem passíveis de ataque pelo agente oxidante (Filho \& Sakaguti, 2008).

Tabela 1: Resultados das análises microbiológicas para bolores e leveduras, coliformes totais e termotolerantes e Salmonella spp., de amora-preta sanitizadas com cloro

\begin{tabular}{|c|c|c|c|c|c|}
\hline Polpas Cloro & Fungos (UFC.g $\left.{ }^{-1}\right)$ & CT (NMP.g $\left.{ }^{-1}\right)$ & CTT (NMP.g ${ }^{-1}$ ) & E. coli & Salmonella spp. \\
\hline Sem tratamento & $3,75 \times 10^{6}$ & Ausência & Ausência & Ausência & Ausência \\
\hline $50 \mathrm{ppm} / 5 \mathrm{~min}$ & $2,26 \times 10^{6}$ & 4 & 4 & Presença & Ausência \\
\hline $50 \mathrm{ppm} / 15 \mathrm{~min}$ & $1,3 \times 10^{6}$ & Ausência & Ausência & Ausência & Ausência \\
\hline $100 \mathrm{ppm} / 5 \mathrm{~min}$ & $9,75 \times 10^{5}$ & $<0,3$ & Ausência & Ausência & Ausência \\
\hline $100 \mathrm{ppm} / 15 \mathrm{~min}$ & $7,45 \times 10^{5}$ & Ausência & Ausência & Ausência & Ausência \\
\hline $150 \mathrm{ppm} / 5 \mathrm{~min}$ & $3,5 \times 10^{4}$ & Ausência & Ausência & Ausência & Ausência \\
\hline $150 \mathrm{ppm} / 15 \mathrm{~min}$ & $2,2 \times 10^{4}$ & Ausência & Ausência & Ausência & Ausência \\
\hline $200 \mathrm{ppm} / 5 \mathrm{~min}$ & $6,5 \times 10^{3}$ & Ausência & Ausência & Ausência & Ausência \\
\hline $200 \mathrm{ppm} / 15 \mathrm{~min}$ & $4 \times 10^{3}$ & Ausência & Ausência & Ausência & Ausência \\
\hline Padrão Federal* & $5 \times 10^{3 *}$ & $1^{*}$ & $10^{2 * *}$ & - & Ausência em 25 g* \\
\hline
\end{tabular}

Legenda: CT - coliformes totais; CTT- coliformes termotolerantes; * Instrução Normativa n ${ }^{\circ} 1$ de 07 jan de 2000 (Brasil 2000);** RDC n ${ }^{\circ} 12$, de 02/01/ 2001 (Brasil, 2001). Todas as análises foram feitas em triplicata.

Tabela 2: Resultados das análises microbiológicas para bolores e leveduras, coliformes totais e termotolerantes e Salmonella, da frutas sanitizadas com ozônio

\begin{tabular}{|c|c|c|c|c|c|}
\hline PolpasOzônio & Fungos (UFC.g ${ }^{-1}$ ) & CT (NMP.g $\left.{ }^{-1}\right)$ & CTT (NMP.g-1 $\left.{ }^{-1}\right)$ & E. coli & Salmonella spp. \\
\hline Sem tratamento & $3,75 \times 10^{6}$ & Ausência & Ausência & Ausência & Ausência \\
\hline $1,75 \mathrm{ppm}$ & $5 \times 10^{3}$ & Ausência & Ausência & Ausência & Ausência \\
\hline 3 ppm4 ppm & $3,73 \times 10^{3} 2 \times 10^{2}$ & Ausência & Ausência & AusênciaAusência & Ausência Ausência \\
\hline Padrão Federal & $5 \times 10^{3 *}$ & $1^{*}$ & $10^{2^{* *}}$ & - & Ausência em $25 \mathrm{~g}^{8}$ \\
\hline
\end{tabular}

CT - coliformes totais; CTT- coliformes termotolerantes; * Instrução Normativa n ${ }^{\circ} 1$ de 07 jan de 2000 (Brasil 2000); **RDC n 12, de 02/01/2001 (Brasil, 2001). Todas as análises realizadas em triplicata. 
Tabela 3: Conteúdos de compostos fenólicos e de antocianinas totais, em amoras-pretas submetidas à sanitização com cloro e ozônio

Compostos Fenólicos Individuais (mg.100g-1)

\begin{tabular}{|c|c|c|c|c|c|c|c|}
\hline Cloro & Ácido Gálico & $\begin{array}{c}\text { Ácido } \\
\text { Hidroxi-Benzoico }\end{array}$ & Catequina & Epicatequina & Querce-Tina & Total C.P* & $\begin{array}{l}\text { Antocianinas Totais } \\
\left(\mathbf{m g . 1 0 0 g ^ { - 1 } )}\right.\end{array}$ \\
\hline $\mathrm{S} / \mathrm{TT}$ & $278,84 \pm 12,48^{\mathrm{a}}$ & $237,95 \pm 10,21^{\mathrm{a}}$ & $10,21 \pm 1,22^{\mathrm{a}}$ & $160,79 \pm 11,71^{\mathrm{a}}$ & $22,20 \pm 1,33^{\mathrm{a}}$ & 709,98 & $110,73 \pm 10,48^{a}$ \\
\hline $50 \mathrm{ppm}(5 \mathrm{~min})$ & $264,21 \pm 16,33^{\mathrm{a}}$ & $222,5 \pm 12,33^{\mathrm{a}}$ & $10,25 \pm 1,52^{\mathrm{a}}$ & $155,00 \pm 10,41^{\mathrm{a}}$ & $20,5 \pm 3,22^{\mathrm{a}}$ & 672,75 & $109,90 \pm 11,22^{\mathrm{a}}$ \\
\hline $50 \mathrm{ppm}(15 \mathrm{~min})$ & $220,11 \pm 8,48^{a}$ & $190,54 \pm 18,49^{a}$ & $5,90 \pm 1,43^{b}$ & $154,23 \pm 9,72^{\mathrm{a}}$ & $19,14 \pm 3,76^{\mathrm{a}}$ & 589,92 & $107,80 \pm 13,1^{\mathrm{a}}$ \\
\hline $100 \mathrm{ppm}(5 \mathrm{~min})$ & $202,80 \pm 9,21^{a}$ & $167,49 \pm 9,42^{\mathrm{b}}$ & $10,10 \pm 2,22^{a}$ & $155,48 \pm 12,88^{\mathrm{a}}$ & $20,02 \pm 2,22^{\mathrm{a}}$ & 555,89 & $111,90 \pm 9,57^{a}$ \\
\hline $100 \mathrm{ppm}(15 \mathrm{~min})$ & $168,75 \pm 15,12^{b}$ & $94,99 \pm 7,21^{\mathrm{c}}$ & $8,68+2,21^{\mathrm{a}}$ & $138,25 \pm 8,91^{\mathrm{b}}$ & $14,88 \pm 2,55^{\mathrm{a}}$ & 425,55 & $110,76 \pm 8,95^{\mathrm{a}}$ \\
\hline $150 \mathrm{ppm}(5 \mathrm{~min})$ & $167,88 \pm 14,55^{\mathrm{b}}$ & $89,99 \pm 5,53^{c}$ & $7,99 \pm 1,67^{\mathrm{a}}$ & $135,23 \pm 9,22^{b}$ & $15,01 \pm 3,18^{a}$ & 416,10 & $100,09 \pm 10,07^{a}$ \\
\hline $150 \mathrm{ppm}(5 \mathrm{~min})$ & $158,80 \pm 5,12^{b}$ & $88,88 \pm 4,22^{\mathrm{c}}$ & $5,67 \pm 2,33^{b}$ & $126,88 \pm 9,94^{b}$ & $12,09 \pm 1,77^{\mathrm{b}}$ & 392,32 & $90,88+9,98^{\mathrm{a}}$ \\
\hline $200 \mathrm{ppm}(5 \mathrm{~min})$ & $145,78 \pm 11,39^{\mathrm{b}}$ & $70,90 \pm 1018^{c}$ & $3,61 \pm 0,88^{c}$ & $85,01 \pm 7,82^{\mathrm{c}}$ & $12,65 \pm 1,31^{\mathrm{b}}$ & 317,95 & $77,09 \pm 5,56^{\mathrm{b}}$ \\
\hline $200 \mathrm{ppm} / 15 \mathrm{~min}$ & $134,99 \pm 17,12^{b}$ & $71,09 \pm 9,89^{c}$ & $3,09 \pm 0,96^{c}$ & $84,98 \pm 5,29^{c}$ & $13,04 \pm 1,72^{\mathrm{b}}$ & 307,19 & $75,06 \pm 4,27^{b}$ \\
\hline \multicolumn{8}{|l|}{ OZÔNIO } \\
\hline $1,75 \mathrm{ppm}$ & $273,05 \pm 9,22^{a}$ & $233,5 \pm 7,25^{\mathrm{a}}$ & $9,89 \pm 1,92^{\mathrm{a}}$ & $154,00 \pm 6,29^{a}$ & $21,5 \pm 4,87^{\mathrm{a}}$ & 691,94 & $110,9 \pm 2,52^{\mathrm{a}}$ \\
\hline $3 \mathrm{ppm}$ & $270,08 \pm 9,43^{a}$ & $188,33 \pm 5,22^{\mathrm{b}}$ & $7,80 \pm 0,77^{\mathrm{b}}$ & $154,03 \pm 5,74^{\mathrm{a}}$ & $20,5 \pm 3,32^{\mathrm{a}}$ & 640,74 & $109,78 \pm 3,62^{\mathrm{a}}$ \\
\hline $4 \mathrm{ppm}$ & $268,66 \pm 8,29^{a}$ & $175,22 \pm 8,18^{b}$ & $7,65 \pm 0,85^{b}$ & $146,88 \pm 6,84^{\mathrm{a}}$ & $17,94 \pm 4,11^{\mathrm{a}}$ & 616,35 & $109,55 \pm 1,82^{\mathrm{a}}$ \\
\hline
\end{tabular}

*Soma dos compostos fenólicos individuais

**S/TT: Sem tratamento

\pm Desvio padrão; * letras diferentes na mesma coluna indicam diferença significativa a 95\%. Todas as análises realizadas em triplicata. 
É difícil prever o comportamento cinético do cloro em meio aquoso, bem como a formação de subprodutos da desinfecção, sem que sejam conduzidos ensaios experimentais específicos. Porém, pode-se observar, neste estudo, que o processo de sanitização ocasionou uma redução do conteúdo dos compostos fenólicos individuais em geral e do conteúdo de antocianinas. O conteúdo de antocianinas foi reduzido em torno de $32 \%$, após as amostras serem submetidas a tratamento com solução clorada mais concentrada (200 ppm) e no maior tempo de exposição (15 min), sendo que esta foi a única solução eficiente na sanitização contra bolores e leveduras. O conteúdo de compostos fenólicos, calculado pela soma dos conteúdos dos compostos fenólicos individuais, na amostra submetida à higienização apenas em água pura (sem tratamento), quando comparado com o da amostra submetida à sanitização com cloro a 200 ppm, por 15 min., reduziuse em $56 \%$. Dentre os compostos fenólicos, o ácido hidroxibenzoico foi o mais afetado, tendo seu teor sido reduzido em $70 \%$ após a sanitização.

Nas amostras sanitizadas com ozônio, não se observou diferença significativa, entre os tratamentos, nos conteúdos do ácido gálico, da epicatequina e da quercetina. Diferenças também não foram observadas no conteúdo de antocianinas. Assim, ficou evidenciado que, mesmo nas baixas concentrações de ozônio utilizadas, ocorreu efetividade da sanitização, e que soluções ozonizadas ocasionaram apenas pequenas perdas dos compostos analisados, mostrando, assim, ser um método de sanitização eficiente, tanto na redução de micro-organismo quanto para a retenção de compostos bioativos.

Na Tabela 4, estão os resultados dos conteúdos de tocoferóis e de ácido ascórbico das frutas sanitizadas com cloro e ozônio.

A vitamina $\mathrm{E}$ é encontrada, principalmente, em produtos que apresentam alto teor em gordura, por serem compostos solúveis em meios lipofílicos, como em amêndoas, óleos vegetais e em alguns frutos e vegetais (Lins, 2006). A amora-preta apresentou uma quantidade muito baixa de tocoferóis, o que pode ser explicado pelo baixo conteúdo de gordura presente nesse fruto. Chun et al. (2006) relatam conteúdo de $3,74 \mathrm{mg} \cdot 100 \mathrm{~g}^{-1} \mathrm{de}$ tocoferóis em amora-preta, valor superior ao encontrado neste estudo $\left(0,87 \mathrm{mg} \cdot 100 \mathrm{~g}^{-1}\right)$, o que pode ser parcialmente explicado pelas diferenças entre cultivares, espécies e clima, dentre outros.

Pode-se observar que ocorreram diferenças significativas no conteúdo de tocoferóis nas amostras submetidas aos diferentes tratamentos com cloro, a partir da concentração de 100 pmm, mostrando uma redução de até $35 \%$, na amostra submetida ao tratamento com solução de concentração de $200 \mathrm{ppm}$. As amostras, submetidas aos diferentes tratamentos com ozônio, não apre- sentaram diferenças significativas no conteúdo de tocoferóis, quando comparadas com as amostras sem tratamento.

Vários trabalhos avaliaram o efeito sobre o ácido ascórbico durante o processamento de frutas e hortaliças; no entanto, não foram encontrados relatos sobre a estabilidade dessa vitamina apenas relacionada com o processo de sanitização. As perdas de ácido ascórbico, decorrentes dos diferentes processos de sanitização, precisam ser avaliadas, para garantir maior exatidão no planejamento de dietas, bem como na avaliação dietética de indivíduos.

A vitamina $\mathrm{C}$ apresenta propriedades antioxidantes; portanto processos de sanitização por meio de soluções que contenham compostos com poder oxidante possam agir na redução do teor dessa vitamina. De acordo com Ozkan et al. (2004), por causa de sua instabilidade o ácido ascórbico tem sido utilizado como indicador da qualidade nutricional de frutas e hortaliças. Neste estudo, foram observadas as maiores perdas dessa vitamina na sanitização com cloro na maior concentração (200ppm), atingindo cerca de $55 \%$. No entanto, nas amostras submetidas ao processo de sanitização com ozônio, não foi observada alteração do conteúdo de vitamina $\mathrm{C}$.

$\mathrm{Na}$ Tabela 5, estão os dados dos conteúdos de tocoferóis e de ácido ascórbico das frutas sanitizadas com cloro e ozônio.

Quando se comparam as perdas com os outros compostos bioativos avaliados, pode-se observar que as perdas de carotenoides não foram tão significativas, quando as amostras foram tratadas com cloro. Isto suporta estudos de Jacques \& Zambiazi (2009), os quais deduzem que esse pigmento, além de se encontrar em pequena quantidade na amora-preta, pode-se encontrar protegido por outros compostos contra processos de oxidação. Nas concentrações das soluções e tempos utilizados, até $100 \mathrm{ppm}$ de cloro e tempo de imersão de 15 minutos, não houve diferenças significativas, a $5 \%$ de significância, no teor de carotenoides.

Costa et al. (2003) relatam que ocorreu maior instabilidade de $\beta$-criptoxantina, em comparação com a de $\beta$-caroteno, na polpa de acerola. A mesma tendência foi observada neste estudo com a amora-preta, pois o conteúdo de $\beta$-caroteno permaneceu praticamente estável nas concentrações utilizadas, diferentemente do comportamento observado com o conteúdo de $\beta$-criptoxantina, o qual se apresentou mais sensível ao aumento da concentração de cloro do que os demais carotenoides.

Os teores de luteína e de zeaxantina na polpa de amora-preta $\left(0,490 \mathrm{mg} \cdot 100 \mathrm{~g}^{-1}\right)$ são superiores aos teores relatados por Rosso \& Mercadante (2005) para acerola $\left(0,100 \mathrm{mg} \cdot 100 \mathrm{~g}^{-1}\right)$. 
Tabela 4: Conteúdos de tocoferóis e de ácido ascórbico na polpa de amora-preta cv. Tupy, submetidas aos diferentes tratamentos com cloro e ozônio

\begin{tabular}{|c|c|c|c|c|c|}
\hline \multicolumn{6}{|c|}{ Tocoferóis (mg.100 $\left.\mathrm{g}^{-1}\right)$} \\
\hline CLORO & $\delta$ Tocoferol & $(\beta+\gamma)$ - Tocoferol & $\alpha$-Tocoferol & Total $(\alpha+\beta+\gamma+\delta)$ & Ácido ascórbico \\
\hline Sem tratamento & $0,49 \pm 0,09^{\mathrm{A}}$ & $0,24 \pm 0,11^{\mathrm{A}}$ & $0,12 \pm 0,07^{\mathrm{A}}$ & $0,87 \pm 0,09^{\mathrm{A}}$ & $1,08 \pm 0,15^{\mathrm{A}}$ \\
\hline $50 \mathrm{ppm} / 5 \mathrm{~min}$ & $0,48 \pm 0,08^{\mathrm{A}}$ & $0,24 \pm 0,09^{\mathrm{A}}$ & $0,12 \pm 0,09^{\mathrm{A}}$ & $0,85 \pm 0,08^{\mathrm{A}}$ & $0,99 \pm 0,10^{\mathrm{A}}$ \\
\hline $50 \mathrm{ppm} / 15 \mathrm{~min}$ & $0,48 \pm 0,10^{\mathrm{A}}$ & $0,24 \pm 0,11^{\mathrm{A}}$ & $0,12 \pm 0,08^{\mathrm{A}}$ & $0,85 \pm 0,17^{\mathrm{A}}$ & $0,97 \pm 0,09^{\mathrm{A}}$ \\
\hline $100 \mathrm{ppm} / 5 \mathrm{~min}$ & $0,40 \pm 0,09^{\text {в }}$ & $0,20 \pm 0,08^{\text {в }}$ & $0,10 \pm 0,07^{\text {в }}$ & $0,70 \pm 0,08^{\text {в }}$ & $0,76 \pm 0,08^{\mathrm{B}}$ \\
\hline $100 \mathrm{ppm} / 15 \mathrm{~min}$ & $0,40 \pm 0,08^{\text {в }}$ & $0,19 \pm 0,09^{\text {в }}$ & $0,10 \pm 0,06^{\mathrm{B}}$ & $0,70 \pm 0,06^{\mathrm{B}}$ & $0,78 \pm 0,06^{\mathrm{B}}$ \\
\hline $150 \mathrm{ppm} / 5 \mathrm{~min}$ & $0,35 \pm 0,17^{\mathrm{C}}$ & $0,13 \pm 0,07^{\mathrm{C}}$ & $0,10 \pm 0,09^{\mathrm{B}}$ & $0,59 \pm 0,04^{\mathrm{C}}$ & $0,58 \pm 0,06^{\mathrm{C}}$ \\
\hline $150 \mathrm{ppm} / 15 \mathrm{~min}$ & $0,35 \pm 0,08^{\mathrm{C}}$ & $0,12 \pm 0,09^{\mathrm{C}}$ & $0,11 \pm 0,08^{\text {в }}$ & $0,59 \pm 0,05^{\mathrm{c}}$ & $0,57 \pm 0,08^{\mathrm{c}}$ \\
\hline $200 \mathrm{ppm} / 5 \mathrm{~min}$ & $0,34 \pm 0,09^{\mathrm{C}}$ & $0,12 \pm 0,10^{\mathrm{C}}$ & $0,09 \pm 0,10^{\text {в }}$ & $0,55 \pm 0,09^{\mathrm{c}}$ & $0,49 \pm 0,04^{\mathrm{C}}$ \\
\hline $200 \mathrm{ppm} / 15 \mathrm{~min}$ & $0,33 \pm 0,07^{\mathrm{C}}$ & $0,11 \pm 0,10^{\mathrm{C}}$ & $0,08 \pm 0,09^{\mathrm{B}}$ & $0,54 \pm 0,07^{\mathrm{C}}$ & $0,49 \pm 0,06^{\mathrm{C}}$ \\
\hline \multicolumn{6}{|l|}{ OZÔNIO } \\
\hline $1,75 \mathrm{ppm}$ & $0,490 \pm 0,03^{\mathrm{a}}$ & $0,246 \pm 0,01^{\mathrm{a}}$ & $0,121 \pm 0,01^{a}$ & $0,866 \pm 0,02^{\mathrm{a}}$ & $1,09 \pm 0,02^{\mathrm{a}}$ \\
\hline $3 \mathrm{ppm}$ & $0,491 \pm 0,02^{\mathrm{a}}$ & $0,245 \pm 0,04^{\mathrm{a}}$ & $0,122 \pm 0,02^{a}$ & $0,869 \pm 0,03^{a}$ & $0,989 \pm 0,02^{\mathrm{a}}$ \\
\hline $4 \mathrm{ppm}$ & $0,493 \pm 0,05^{a}$ & $0,246 \pm 0,05^{\mathrm{a}}$ & $0,123 \pm 0,03^{a}$ & $0,865 \pm 0,01^{\mathrm{a}}$ & $1,03 \pm 0,03^{\mathrm{a}}$ \\
\hline
\end{tabular}

*Soma dos compostos fenólicos individuais

**S/TT: Sem tratamento

\pm Desvio padrão; * letras diferentes na mesma coluna indicam diferença significativa a 95\% . Todas as análises realizadas em triplicata.

Tabela 5: Conteúdo de carotenoides na polpa de amora-preta cv. Tupy, submetidas aos tratamentos com cloro e ozônio

\begin{tabular}{|c|c|c|c|c|c|}
\hline \multicolumn{6}{|c|}{ Carotenoides (mg.100 $\left.\mathrm{g}^{-1}\right)$} \\
\hline Cloro & $\beta$-Criptoxantina & $\begin{array}{c}\text { Luteína + } \\
\text { Zeaxantina }\end{array}$ & $\beta$-caroteno & Licopeno & Total \\
\hline Sem tratamento & $0,250 \pm 0,09^{\mathrm{A}}$ & $0,490 \pm 0,09^{\mathrm{A}}$ & $0,007 \pm 0,002^{\mathrm{A}}$ & $0,014 \pm 0,03^{\mathrm{A}}$ & $0,761 \pm 0,08^{\mathrm{A}}$ \\
\hline $50 \mathrm{ppm} / 5 \mathrm{~min}$ & $0,249 \pm 0,08^{\mathrm{A}}$ & $0,487 \pm 0,11^{\mathrm{A}}$ & $0,007 \pm 0,004^{\mathrm{A}}$ & $0,010 \pm 0,002^{\mathrm{B}}$ & $0,754 \pm 0,07^{\mathrm{A}}$ \\
\hline $50 \mathrm{ppm} / 15 \mathrm{~min}$ & $0,251 \pm 0,10^{\mathrm{A}}$ & $0,488 \pm 0,12^{\mathrm{A}}$ & $0,007 \pm 0,003^{\mathrm{A}}$ & $0,011 \pm 0,003^{\mathrm{B}}$ & $0,757 \pm 0,07^{\mathrm{A}}$ \\
\hline $100 \mathrm{ppm} / 5 \mathrm{~min}$ & $0,240 \pm 0,11^{\mathrm{A}}$ & $0,479 \pm 0,08^{\mathrm{A}}$ & $0,006 \pm 0,003^{\mathrm{A}}$ & $0,009 \pm 0,002^{\mathrm{B}}$ & $0,734 \pm 0,05^{\mathrm{A}}$ \\
\hline $100 \mathrm{ppm} / 15 \mathrm{~min}$ & $0,241 \pm 0,11^{\mathrm{A}}$ & $0,475 \pm 0,7^{\mathrm{A}}$ & $0,007 \pm 0,001^{\mathrm{A}}$ & $0,010 \pm 0,002^{\mathrm{B}}$ & $0,733 \pm 0,09^{\mathrm{A}}$ \\
\hline $150 \mathrm{ppm} / 5 \mathrm{~min}$ & $0,235 \pm 0,08^{\mathrm{B}}$ & $0,420 \pm 0,04^{\mathrm{B}}$ & $0,005 \pm 0,002^{\mathrm{A}}$ & $0,006 \pm 0,004^{c}$ & $0,666 \pm 0,03^{\mathrm{B}}$ \\
\hline $150 \mathrm{ppm} / 15 \mathrm{~min}$ & $0,221 \pm 0,07^{\mathrm{B}}$ & $0,395 \pm 0,07^{\mathrm{B}}$ & $0,005 \pm 0,002^{\mathrm{A}}$ & $0,007 \pm 0,002^{\mathrm{c}}$ & $0,628 \pm 0,02^{\mathrm{B}}$ \\
\hline $200 \mathrm{ppm} / 5 \mathrm{~min}$ & $0,218 \pm 0,08^{\mathrm{B}}$ & $0,399 \pm 0,06^{\mathrm{B}}$ & $0,005 \pm 0,003^{\mathrm{A}}$ & $0,006 \pm 0,003^{c}$ & $0,628 \pm 0,05^{\mathrm{B}}$ \\
\hline $200 \mathrm{ppm} / 15 \mathrm{~min}$ & $0,215 \pm 0,06^{\mathrm{B}}$ & $0,394 \pm 0,09^{\mathrm{B}}$ & $0,005 \pm 0,002^{\mathrm{A}}$ & $0,007 \pm 0,003^{c}$ & $0,621 \pm 0,05^{\mathrm{B}}$ \\
\hline \multicolumn{6}{|l|}{ Ozônio } \\
\hline $1,75 \mathrm{ppm}$ & $0,245 \pm 0,09^{\mathrm{A}}$ & $0,491 \pm 0,03^{\mathrm{A}}$ & $0,007 \pm 0,001^{\mathrm{A}}$ & $0,013 \pm 0,003^{\mathrm{A}}$ & $0,758 \pm 0,02^{\mathrm{A}}$ \\
\hline $3 \mathrm{ppm}$ & $0,244 \pm 0,09^{\mathrm{A}}$ & $0,488 \pm 0,02^{\mathrm{A}}$ & $0,007 \pm 0,002^{\mathrm{A}}$ & $0,014 \pm 0,003^{\mathrm{A}}$ & $0,762 \pm 0,05^{\mathrm{A}}$ \\
\hline $4 \mathrm{ppm}$ & $0,246 \pm 0,09^{\mathrm{A}}$ & $0,490 \pm 0,03^{\mathrm{A}}$ & $0,007 \pm 0,002^{\mathrm{A}}$ & $0,012 \pm 0,004^{\mathrm{A}}$ & $0,755 \pm 0,02^{\mathrm{A}}$ \\
\hline
\end{tabular}

*Soma dos carotenoides individuais

**S/TT: Sem tratamento

\pm Desvio padrão; * letras diferentes na mesma coluna indicam diferença significativa a $95 \%$.

Com relação ao teor de licopeno, pode-se observar que houve diferenças significativas em todas as concentrações de cloro e tempos de imersão. O licopeno é composto por onze ligações conjugadas e duas ligações duplas não conjugadas e, por isso, é considerado um dos carotenoides com uma das maiores capacidades sequestrantes do oxigênio singlete, (Shami \& Moreira, 2004), podendo esta ser uma das causas da maior influência dos tratamentos utilizados com o cloro, por este ser um potente oxidante.
Os resultados observados para os frutos sanitizados com ozônio seguiram o mesmo padrão, ou seja, não foram observadas diferenças significativas no conteúdo de carotenoides, em função da concentração de ozônio aplicada e do tempo de exposição, quando comparados com o da amostra submetida apenas à água pura (sem tratamento), indicando que o ozônio, nas concentrações e tempo utilizados neste estudo, não afetou o conteúdo de carotenoides das amostras. 


\section{CONCLUSÃO}

Os compostos de cloro utilizados na sanitização dos frutos foram eficientes contra fungos em amorapreta, quando utilizados na concentração de 200 ppm, por 15 minutos de imersão; porém, induziram a perdas significativas dos compostos bioativos naturalmente presentes na amora-preta cv. Tupy. Já os frutos de amora-preta sanitizados com ozônio apresentaram adequação aos padrões microbiológicos estabelecidos pela legislação brasileira e não apresentaram alterações significativas de conteúdo dos compostos bioativos, sendo que a menor concentração de ozônio presente neste estudo apresentou maior eficácia na sanitização dos frutos, se comparada com a eficácia das soluções de cloro utilizadas.

\section{REFERÊNCIAS}

Andrade NJ \& Martyn MEL (1996) Limpeza e sanitização na indústria de alimentos. Viçosa, Universidade Federal de Viçosa. 39p.

Antoniolli LR, Benedeti BC, Filho MMS \& Borges MF (2005) Efeito do hipoclorito de sódio sobre a microbiota de abacaxi 'pérola' minimamente processado. Revista Brasileira de Fruticultura, 27:157-160.

Ayhan Z, Yeom HW \& Zhang QH (2001) Flavour, color, and vitamin C retention of pulsed electric field processed orange juice in different packaging materials. Journal of Agricultural and Food Chemistry, 49:669-674

Brasil (2000) Instrução Normativa n ${ }^{\circ}$ 01, de 07 de janeiro de 2000. Regulamento técnico geral para fixação dos padrões de identidade e qualidade para polpa de fruta. DOU, 10/01/2000, Seção 1, p.259.

Brasil (2001) Resolução RDC n. 12, de 02 janeiro de 2001. Aprova o Regulamento técnico sobre padrões microbiológicos para alimentos. DOU, 02/01/2001, Seção 1, p.174.

Banwart GJ (1989) Basic food microbiology. 2a ed. New York, Van Nostrand Reinhold. 774p.

Brunini MA, Durigan JF \& Oliveira AL (2002) Avaliação das alterações em polpa de manga "Tommy-Atkins" congeladas. Revista Brasileira de Fruticultura, 24:651-653.

Costa ATS, Abreu LN \& Guimarães AG (2003) Efeito do congelamento e do tempo de estocagem da polpa de acerola sobre o teor de carotenoides. Revista Brasileira de Fruticultura, 25:56-58.

Chun J, Lee J, Ye L, Exler J \& Eitenmiller RR (2006) Tocopherol and tocotrienol contents of raw and processed fruits and vegetables in the United States diet. Journal of Food Composition and Analysis, 19:96-204.

Daubeny HA (1996) Brambles. In: Moore JN \& Janick J (Eds.) Fruit Breeding. London, John Wiley \& Sons. p.109-190.

Degáspari CH \& Waszczynskyj N (2004) Propriedades antioxidantes de compostos fenólicos. Visão Acadêmica, 5:33-40.

Downes FP \& Ito H (2001) Compendium of methods for the microbiological examination of foods. Washington, American Public Health Association (APHA). 676p.

Filho SSF \& Sakagutti MI (2008) Comportamento cinético do cloro livre em meio aquoso e formação de subprodutos da desinfecção. Engenharia Sanitária e Ambiental, 13:198-206.

Franco BDG \& Landgraf M (2003) Microbiologia de alimentos. São Paulo, Editora Atheneu. 182p.
Hakkinem SH, Karenlampi SO \& Heinonem M (1998) HPLC Method for Screening of Flavonoids and Phenolic Acids in Berries. Journal Science Food Agricultural, 77:543-551.

Jacques AC \& Zambiazi RC (2009) Amora Preta: Compostos Bioativos e Voláteis. Tese de Doutorado. Universidade Federal de Pelotas, Pelotas. 98p.

Lapolli FR, Santos LF, Hássemer MEN, Aisse MM \& Piveli RP(2003) Desinfecção de efluentes sanitários por meio da ozonização. In: Gonçalves RF (Ed.) Desinfecção de efluentes sanitários, remoção de organismos patógenos e substâncias nocivas: aplicação para fins produtivos como agricultura, aqüicultura e hidropônica. Vitória, PROSAB. p.169-208.

Lees DH \& Francis FJ (1972) Standardization of pigment analysis in Cranberries. HortScience, 7:83-84.

Leite CC (2000) Avaliação Microbiológica de polpas congeladas de frutas produzidas no Estado da Bahia. Higiene Alimentar, 79:69-73.

Lima JR, Martins SCS \& Silva JLA (2001) Avaliação de popas de frutas congeladas comercializadas no estado do Ceará através de indicadores microbiológicos. Higiene Alimentar, 88:62-66.

Lins RT (2006) Determinação de tocoferóis e carotenóides em frutas amazônicas: Implantação de uma metodologia. Dissertação de Mestrado. Universidade Federal do Pará, Belém. 80p.

Nascimento AR, Ferreira FF, Mouchrek JEF \& Cantanhede FB (1999) Perfil microbiológico de polpas de acerola (Malpighia glabal) e abacaxi (Ananas comosus), produzidas e comercializadas na ilha de São Luís, MA. Higiene Alimentar, 62:44-47.

Ozkan M, Kirca A \& Cemeroglu B (2004) Effects of hydrogen peroxide on the stability of ascorbic acid during storage in various fruit juices. Food Chemistry, 88:591-597.

Rodrigues-Amaya BB (2001) A guide to carotenoid analysis in foods. Washington, ILST. 64p

Rosso VV \& Mercadante AZ (2005) Identification and quantification of carotenoids, by HPLC-PDA-MS/MS, from Amazonian fruits. Food Research International, 38:1073-1077.

Silva N, Junqueira VCA \& Silveira NFA (1997) Manual de Métodos de Análise Microbiológica de Alimentos. São Paulo, Livraria Varela. 296p.

Shami NJIE \& Moreira EAM (2004) Licopeno como agente antioxidante. Revista Nutrição, 17:227-236.

Zambiazi RC (1997) The role of endogenous lipid components on vegetabl e oil stability. Tese de Doutorado. University of Manitoba, Winnipeg. 304p.

Rev. Ceres, Viçosa, v. 62, n.6, p. 507-515, nov-dez, 2015 